\title{
Reward magnitude and shock variables (continuity and intensity) in shuttlebox-avoidance learning
}

\author{
DOROTHY E. MCALLISTER, WALLACE R. McALLISTER, and STEPHEN E. DIETER \\ Northern Illinois University, DeKalb, Illinois 60115
}

\begin{abstract}
In Experiment I, eight groups of rats $(n=20)$ were given shuttlebox-avoidance training. Two levels of shock $(.3$ and $1.6 \mathrm{~mA})$ were combined factorially with two levels of reward (large and small) under both continuous and discontinuous $1.75 \mathrm{sec}$ on and $2.00 \mathrm{sec}$ off) shock. Visual situational cues were absent after a shuttle response for the large-reward condition and present for the small-reward condition. Superior performance was obtained with weak rather than strong shock under both reward conditions and with large rather than small reward only under the weak-shock condition. Continuity of shock had no differential effect on performance. Experiment II allowed the conclusion that the reward effect was attributable to a reinforcement mechanism. The data were taken as support for the effective reinforcement theory, which emphasizes the importance in avoidance learning of fear conditioned to situational cues.
\end{abstract}

In signaled avoidance learning, a discrete stimulus (CS) is presented at some interval of time prior to shock (UCS) onset. If the subject makes an instrumental response (e.g., moves away from the shock area) during the CS-UCS interval, the CS is terminated and shock is avoided. A response occurring after the CS-UCS interval results in the termination of the CS and escape from the shock. Since escape responses predominate early in learning, the subject receives a number of shock presentations. It has consistently been found that the learning of a signaled shuttlebox-avoidance response is superior when weak rather than strong shock is used (e.g., Anisman \& Waller, 1972; Bauer, 1972; Cicala \& Kremer, 1969; Freedman, Hennessy, \& Groner, 1974; Kurtz \& Shafer, 1967; Levine, 1966; McAllister, McAllister, \& Douglass, 1971; Moyer \& Korn, 1964; Theios, Lynch, \& Lowe, 1966). This finding has frequently been considered to be evidence against the two-factor theory of avoidance learning (e.g., D'Amato, 1970, pp. 366-367). The two-factor theory (Mowrer, 1947) holds that classically conditioned fear serves as the motivator and its reduction as the reinforcement for the learning of the instrumental avoidance response. Because more fear should be conditioned with strong than with weak shock, it is argued that a direct, rather than an inverse, relationship should be found

This research, supported in part by Grant BMS71-00845 from the National Science Foundation, was presented at the 1975 meeting of the Midwestern Psychological Association. The authors are indebted to Michael J. Grelle and James H. James for aid in the analysis of the data. Requests for reprints should be sent to Dorothy E. McAllister, Psychology Department, Northern Illinois University, DeKalb, Illinois 60115. between shock intensity and avoidance performance. Such a direct relationship is, in fact, found with a one-way avoidance task (Dieter, in press; Moyer \& Korn, 1966). Hence, the inverse relationship obtained in the shuttlebox task is held to be contrary to the theory. However, critics who use this line of reasoning fail to consider the different characteristics of the one-way and the two-way (shuttlebox) tasks in conjunction with the fact that fear is conditioned not only to the CS but also to situational stimuli (e.g., McAllister \& McAllister, 1962).

In a one-way avoidance task where the subject moves from one compartment of the apparatus to another compartment which is distinctly different, the greater conditioning of fear which occurs as shock intensity increases leads to a greater amount of motivation and of reinforcement (fear reduction), and hence, learning is better with strong than with weak shock. This same increase in conditioned fear with shock intensity has different consequences in a shuttlebox-avoidance task where the instrumental response requires the subject to move back and forth between two identical compartments. In this case, the greater fear of the CS which occurs with increases in shock intensity would increase the motivation and reinforcement for the response, as in the one-way task. However, the similar increment in fear of the situational cues would not have this same effect. This source of fear is the same in both compartments and, hence, cannot be reduced by an avoidance response. Also, as shock intensity increases, the amount of fear present after the response would be greater. All of these circumstances can be treated consistently within the spirit of the 
two-factor theory by an elaboration of the fearreduction hypothesis proposed by McAllister et al. (1971). Their position is that the amount of effective reinforcement for an avoidance response is positively related to the amount of fear reduction occurring with the termination of fear-arousing stimuli (CS and/or situational cues) and negatively related to the amount of fear elicited by the stimuli present following a response. In other words, according to this position, it is not simply the amount of fear reduction which determines the amount of reinforcement, but rather it is the amount of fear reduction relative to the amount of fear which remains following the response. The detrimental effect of strong as compared to weak shock in a shuttlebox task may thus be attributed to a lessened amount of effective reinforcement: The greater fear reduction provided by CS termination is more than offset by the greater amount of fear of situational cues present following the response. Some support for this notion is provided by the data of Campbell and Kraeling (1953), which show that escape learning is better when rats are trained to run from a $200-\mathrm{V}$ to a $100-\mathrm{V}$ shock than from a $400-\mathrm{V}$ to a $200-\mathrm{V}$ shock. The effective reinforcement position with respect to the role of fear in avoidance learning is consonant with the data obtained by Campbell (1956) in his investigation of shock-intensity preferences. $\mathrm{He}$ found that the absolute decrement and the proportional decrement in shock intensity required for learning both increase with shock intensity, at least over the range of shock intensities generally used.

An alternative account of the inverse relationship in the shuttlebox task, which is not inconsistent with two-factor theory, is that competing responses (e.g., freezing or staying) which occur to a greater extent as shock intensity increases interfere with avoidance performance (e.g., Bintz, 1971; Theios et al., 1966). Evidence against this position and support for the effective reinforcement theory was provided in the McAllister et al. (1971) study. After shuttlebox-avoidance training, in which it was found that performance was poorer with strong than with weak shock, the subjects were allowed to jump from one of the shuttlebox compartments to an adjacent distinctively different "safe" box. Neither the CS nor shock was present on these escape-from-fear trials. The speed of escaping to the safe box was significantly faster for the subjects which had previously been trained in the shuttle task with strong shock. Then, further escape-from-fear trials were given in which the CS was presented. The addition of this source of fear increased performance for both shock groups. These results seem to rule out the competing response interpretation of the inverse relationship.
If the strong-shock subjects performed poorly in the avoidance task because competing responses were elicited by the CS or the situational cues, they would not have been expected to outperform the weak-shock subjects in the escape-from-fear task. Therefore, the most likely explanation of the inverse relationship seems to be that there is less reinforcement for the shuttle response with strong than with weak shock.

The emphasis placed by the effective reinforcement interpretation of avoidance learning on the role played by fear of situational cues suggests that any method which reduces this source of fear after the response will improve performance in the shuttlebox. The purpose of the present experiment was to test this implication by removing, after each response, the visual situational cues and, hence, preventing the elicitation of fear conditioned to these stimuli. The effect of this reward manipulation was studied under both strong- and weak-shock conditions. A second purpose was to determine whether the use of discontinuous shock, which has been shown to facilitate shuttlebox-avoidance performance relative to continuous shock (Moyer \& Chapman, 1966), would modify the effect of the other manipulated variables.

\section{EXPERIMENT I}

\section{Method}

Apparatus. The shuttlebox, $444 \mathrm{~mm}$ long $\times 165 \mathrm{~mm}$ wide $\times 152 \mathrm{~mm}$ high, was divided into two identical compartments, painted white. A partition, which separated the compartments, contained a black guillotine door, $57 \mathrm{~mm}$ wide $\times 89 \mathrm{~mm}$ high, which rested on a hurdle $63 \mathrm{~mm}$ high. The floor of each compartment, hinged to serve as a floor switch, consisted of 18 stainless steel rods, $3 \mathrm{~mm}$ in diameter, spaced $13 \mathrm{~mm}$ apart. Scrambled shock, provided by a Grason-Stadler shock generator, Model 700, was the UCS. Hinged to the top of each compartment was a box which served as a cover and which contained two light sources. The bottom of each of these covers consisted of hardware cloth, $86 \mathrm{~mm}$ above which was a pane of ground glass. One light source provided the intertrial illumination $(22 \mathrm{~lx})$ used in the small-reward condition, and the other, the visual component $(811 \mathrm{~lx})$ of the compound CS used in both reward conditions. The two light sources together measured $841 \mathrm{~lx}$. Thus, the onset of the discrete visual CS resulted in an increase in illumination which was approximately the same for the two reward conditions $(811 \mathrm{~lx}$ for large reward and $819 \mathrm{~lx}$ for small reward). The white noise component of the compound $\mathrm{CS}$ was provided by a Grason-Stadler white noise generator, Model $901 \mathrm{~B}$, which increased the ambient noise level in the apparatus from 57 to $60 \mathrm{~dB}$.

Subjects and design. The subjects were 160 naive female hooded rats, 108-132 days of age, from the departmental colony. They were assigned randomly to one of eight groups of 20 subjects each. Fourteen additional subjects were discarded, 10 for apparatus failure, 3 for failing to escape shock on 10 consecutive trials, and 1 for avoiding shock by perching on the hurdle on more than $10 \%$ of the trials.

The groups differed with respect to shock intensity, the continuity of shock, and magnitude of reward. For four of the groups, continuous shock was employed; for the other four, the 
shock was discontinuous (.75 sec on and $2.00 \mathrm{sec}$ of t) Within each continuity-of-shock condition, two shock intensitles (.3 and 1.6 mA) were ordered orthogonal to two magnitudes of reward (large and small). The reward conditions differed with respec: to whether or not intertrial illumination was present In the large-reward condition, there was no intertrial illumination, thus, fear-eliciting visual situational cues were absent following a shuttle response. In the small-reward condition, intertrial illumination was used; thus, a shuttle response did not remove the subject from this source of fear.

Procedure. On the first day of the experiment, each subject was handled for $5 \mathrm{~min}$ and then was allowed to explore each compartment of the apparatus for $10 \mathrm{~min}$ with the guillotine door closed, under the intertrial illumination condition to be used in avoidance training. During handling, the subject was alternately picked up and petted and placed on a table to explore.

On the second day, 100 shuttlebox-avoidance trials were administered. Each trial began with the opening of the guillotine door and the simultaneous presentation of the compound CS. Shock was presented if the subject did not trip the floor switch in the opposite compartment within $5 \mathrm{sec}$ following the onset of the CS. Responses following shock onset resulted in both CS and UCS termination and were recorded as escape responses. A shuttle response occurring within the 5-sec CS-UCS interval resulted in CS termination and avoidance of shock and was recorded as an avoidance response. After a response, the subject remained in the compartment it had entered for a 30 -sec intertrial interval (ITI), after which the next trial was begun. If an escape response did not occur withın $55 \mathrm{sec}$ following UCS onset, the guillotine door was closed, the CS and UCS were terminated, a latency of $60 \mathrm{sec}$ was recorded, and the next trial was begun $30 \mathrm{sec}$ later in the same compartment. Latencies were measured in .01 sec with a Hunter Klockounter from the opening of the guillotine door and CS onset to the depression of the floor in the opposite compartment.

\section{Results and Discussion}

Figure 1 presents the mean percentage of avoidance responses in blocks of 10 trials separately for the two continuity-of-shock conditions. The upper panel shows the performance of the continuousshock groups, and the lower panel, the discontinuousshock groups. It is apparent that, regardless of the continuity of shock, avoidance performance was superior with weak (.3 $\mathrm{mA})$ as compared to strong $(1.6 \mathrm{~mA})$ shock and that large reward $(\mathrm{L})$ resulted in superior performance relative to small reward (S) only when the shock was weak. It also appears that under the weak-shock condition, performance reached an asymptote in about 40 trials, whereas under the strong-shock condition performance continued to improve throughout training. As a consequence, toward the end of training, the performance of the strong-shock groups reached a level comparable to that of the weak-shock, small-reward group.

These observations were confirmed by the results of statistical analyses. A repeated-measures analysis of variance of the percentage of avoidance responses in blocks of 10 trials was computed with shock intensity, continuity of shock, and magnitude of reward as the between-subjects factors and trial blocks as the within-subject factor. This analysis

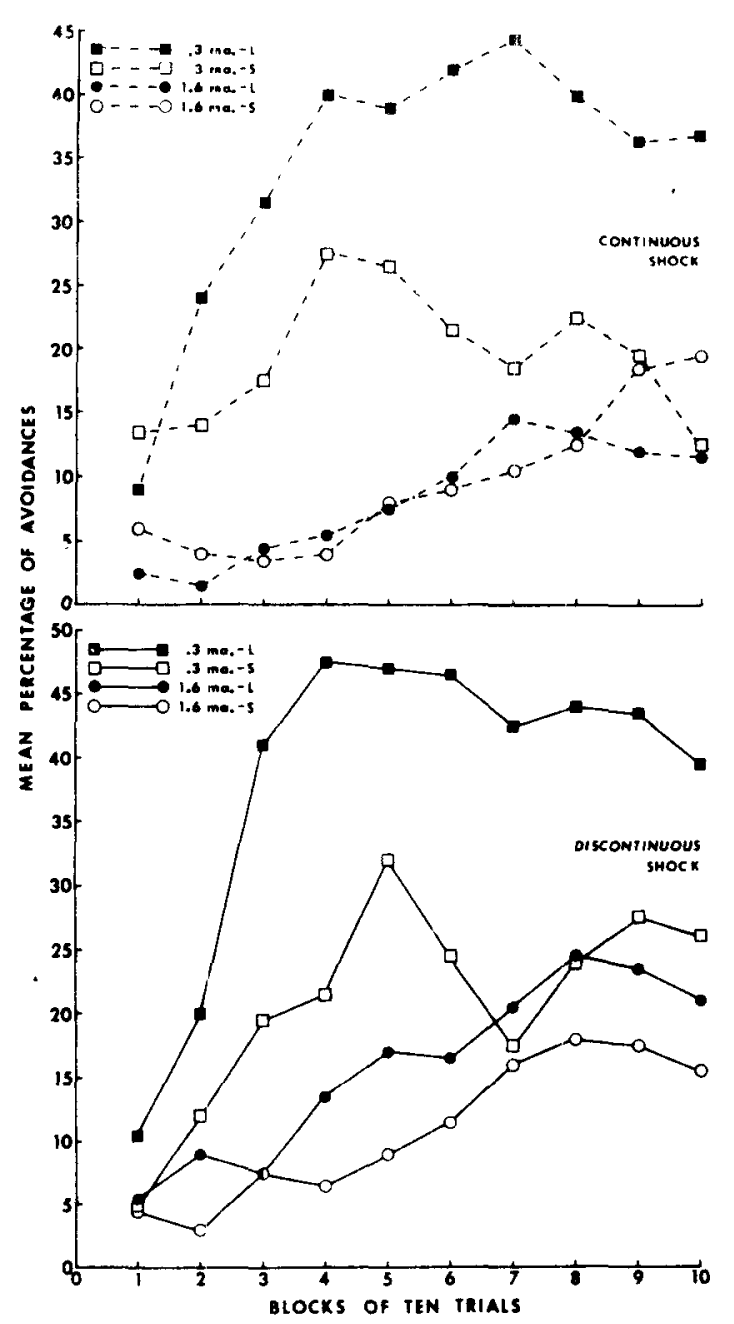

Figure 1. Mean percentage of avoidances as a function of blocks of 10 trials for weak-shock $(.3 \mathrm{~mA})$ and strong-shock (1.6 mA) groups with large (L) and small (S) reward under both continuous and discontinuous shock.

yielded significant effects for shock intensity, $F(1,152)=34.34, p<.001$, magnitude of reward, $\mathrm{F}(1,152)=9.53, \mathrm{p}<.005$, and their interaction, $F(1,152)=6.01, p<.025$. In addition, trial blocks was significant, $\mathrm{F}(9,1368)=22.82, \mathrm{p}<.001$, as well as the interaction of trial blocks with shock intensity, $F(9,1368)=6.98, p<.001$, and with magnitude of reward, $F(9,1368)=2.64, p<.01$. Neither the main effect of continuity of shock nor any of the interactions involving this variable approached significance in this analysis or in any of the other analyses to be reported (ps $>.10$ ).

Because of the interactions with trial blocks, a factorial analysis of variance was computed on the percentage of avoidances at the end of training (Trial Block 10). The interaction between intensity of shock and magnitude of reward was again significant, $F(1,152)=4.98, p<.05$. Therefore, the simple effects were analyzed. Factorial analyses of 


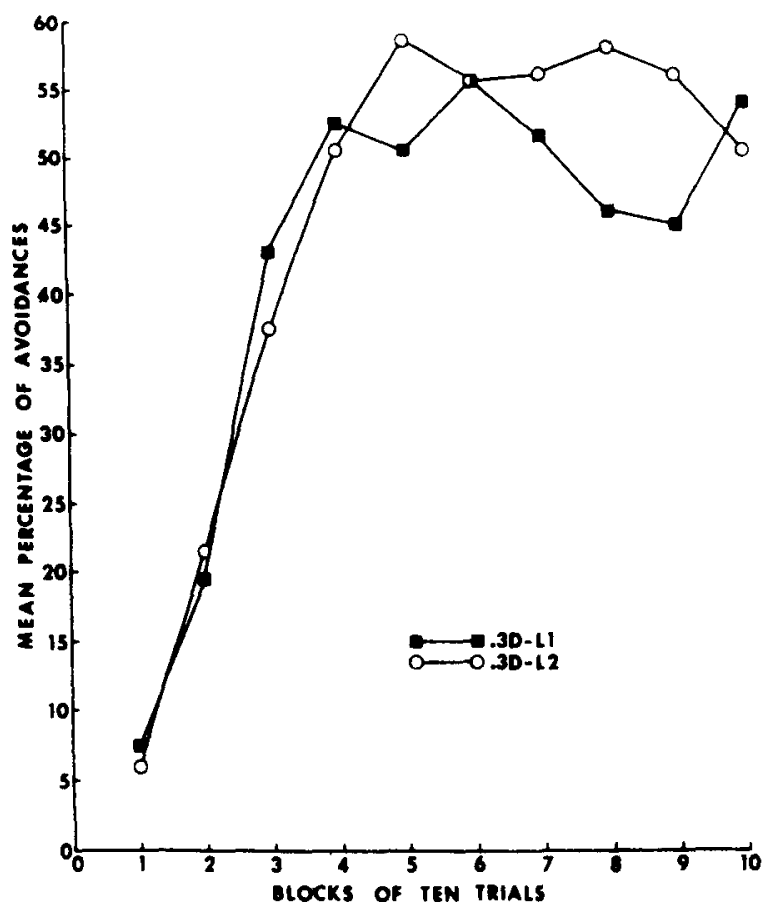

Figure 2. Mean percentage of avoidances as a function of blocks of 10 trials under two large reward conditions. See text for explanation.

variance with magnitude of reward and continuity of shock as the factors indicated that for the weak-shock groups, performance with large reward was significantly superior to that with small reward, $F(1,76)=9.24, p<.005$, whereas for the strongshock groups performance did not differ for the two reward magnitudes, $F(1,76)=.04, p>.20$. A factorial analysis of variance with shock intensity and continuity of shock as the factors indicated that for the large-reward groups performance was significantly better with weak shock than with strong shock, $F(1,76)=9.98, p<.005$, reflecting the typical inverse relationship obtained in shuttleboxavoidance learning. Inspection of the figure indicates that the superiority of weak shock held throughout training. A similar analysis of the performance of the small-reward groups showed no significant effect of shock intensity at the end of training, $F(1,76)=.09, p>.20$. However, analyses of each of the other trial blocks revealed that performance under the small-reward condition was superior with weak shock relative to strong shock on Trial Blocks 2 through 6 (ps $<.01$ ).

Before proceeding to a general discussion of the data, a possible confounding in the procedure used to manipulate reward should be considered. Under the large-reward condition, a shuttle response involved locomoting from a lighted to an unlighted compartment. If rats have a preference for darkness, the superior performance of the large-reward group relative to the small-reward group under the weakshock condition might be attributable, at least in part, to this factor rather than to an increase in effective reinforcement. Even though the failure to find a reward effect under the strong-shock condition contradicts the darkness-preference interpretation, Experiment II was conducted to evaluate this possibility.

\section{EXPERIMENT II}

\section{Method}

Apparatus. The apparatus used was the same as that described for Experiment I.

Subjects and design. The subjects were 40 naive female hooded rats, 114-122 days of age, from the departmental colony. Four additional subjects were discarded for failure 10 escape shock on 10 consecutive trials. The subjects were assigned at random to one of two groups. One group was treated exactly as the $3 \mathrm{~mA}-\mathrm{L}$ discontinuous shock group of Experiment $I$, now designated the .3D-Ll group. The treatment of the other group, designated .3D-L2, was identical except that, when the guillotine door was opened at the beginning of a trial, the ITI light was present in the compartment into which the subject was required to locomote. When the floor switch was tripped after a shuttle response, the ITI illumination was terminated. Thus, in neither group were fear-eliciting visual situational cues present during the ITI following a shuttle response. The groups differed only with respect to whether they Jumped into a darkened compartment (L1) or into a lighted compartment (L2).

Procedure. Except as noted above, all procedures were identical to those used in Experiment I.

\section{Results and Discussion}

The mean percentage of avoidance responses in blocks of 10 trials are plotted for the two groups in Figure 2. As may be readily seen, performance improved over trials in an almost identical manner in the two groups. The statistical analysis supported this observation. A repeated-measures analysis of variance showed no groups effect $(p>.20)$, a significant effect of trial blocks, $F(9,342)=$ $32.13, \mathrm{p}<.001$, and no interaction between the factors $(p>.20)$. These results imply that the significant effect of reward found in the weak-shock condition of Experiment I cannot be attributed to a preference for an unlighted relative to a lighted box.

\section{GENERAL DISCUSSION}

The typical inverse relationship between intensity of shock and acquisition of avoidance responding in the shuttlebox task was obtained reliably in the present experiment. On the basis of the effective reinforcement position, this result was expected for the small-reward condition. However, for the large-reward condition, the usual inverse relationship was expected to be modified depending upon the extent to which the procedures were successful in removing the fear-eliciting situational cues after a response. It follows from the effective reinforcement 
theory that if all such fear were removed, a direct relationship would be found between shock intensity and shuttlebox-avoidance acquisition. The removal of a lesser amount of fear would be expected to eliminate or to decrease the size of the inverse relationship. This expectation was not realized in the present experiment because the reward manipulation was not successful under strong shock. A reasonable explanation is that with strong shock such a large amount of fear was conditioned to the tactual cues of the grid floor that the removal of the fear conditioned to the visual cues was insufficient to increase effective reinforcement. Support for this contention is provided in a recent study by Modaresi (1975). He found that when tactual cues of the grid were removed on each trial of a shuttlebox-avoidance task, by allowing subjects to enter a box with a solid instead of a grid floor, performance was markedly improved. In fact, when the solid floor was used, the usual inverse relationship was eliminated. The present results suggest that if Modaresi had also removed visual fear-arousing cues following a response, the inverse relationship may have been reversed; avoidance performance may have been superior with strong as compared to weak shock. This might be expected since with all fear of situational cues (visual and tactual) absent after a response, the task becomes essentially a one-way task in which there is a direct relationship between avoidance performance and shock intensity (Dieter, in press; Moyer \& Korn, 1966).

With weak shock, the absence of the visual situational cues after the response led to a significant improvement in avoidance performance. The results of Experiment II, which indicated that performance was equally good whether or not the removal of the visual cues was response contingent, implicates a reinforcement mechanism as the basis for the improved performance. That is, at the beginning of a trial, the presence of the dark box in the $\mathrm{L} 1$ reward condition did not produce more avoidance responding than did the presence of the lighted box in the L2 condition. Thus, in Experiment I, it can be held that the absence of the visual situational cues following the response is of critical importance and that the consequence is an increase in effective reinforcement. Results analogous to those of Experiment II have been reported in an escape-from-shock task (Franchina, Bush, Kash, Troen, \& Young, 1973, Experiment 3).

There are theories of avoidance learning which reject the notion that the learning of an avoidance response depends on reinforcement. For instance, it is suggested by Bolles $(1970$, p. 40) "that when CS termination is made contingent on [the avoidance response], it is not reinforcing [the avoidance response] in the usual sense but rather providing
$S$ with information, or feedback. CS termination may merely be a stimulus change which signals that the environment has been altered in some way." That is, as stated by Bolles (1970, p. 44), "CS termination tells the animal, in effecl, that shock is not going to occur."

Several points may be made regarding this position with respect to the present data. In the first place, it would seem that the information or feedback notion alone cannot handle the fact that shuttlebox avoidance acquisition and intensity of shock were found to be related inversely. The information that shock is not going to occur should be the same regardless of the shock intensity. If anything, it might be thought that such information would be more importan as shock intensity increased, and hence, performance would be expected to be better with strong than with weak shock. The reverse is true.

In the second place, the information or feedback position would probably hold that the superior performance of the large- relative to the smallreward group under the weak-shock condition is attributable to an increase in information. That is, the presence of the dark box following the response provided a greater stimulus change than the lighted box. Such an account should also be applicable to the strong-shock groups, but, since the difference in box lighting following the response did not affect performance under this shock condition, the information position is disconfirmed.

In the third place, in contrasting the information with the reinforcement position, Bolles (1970, p. 41) fails to distinguish between the implications of two different notions of reinforcement: (a) that the CS becomes aversive and its termination is reinforcing, and (b) that fear becomes conditioned to the CS and situational cues and fear reduction is reinforcing. The typical type of experiment used to support the information theory in contrast to a reinforcement theory is one involving a feedback stimulus. In these studies (e.g., Bower, Starr, \& Lazarovitz, 1965), it is found that when CS termination is delayed, avoidance performance is degraded. However, if CS termination is delayed but another stimulus is presented after the avoidance response, performance reaches the same level as when CS termination is prompt. Such findings are taken by Bolles to indicate that CS termination and the feedback stimulus both provide information that shock has been avoided. Because CS termination is not a necessary condition for avoidance learning, Bolles argues that reinforcement theory is inadequate. However, these results infirm onlv the CS-aversiveness version of reinforcement theory, because that position has the termination of the CS as its only source of reinforcement. On the other hand, they are consistent with the fear-reduction hypothesis because the change in the 
stimulus complex resulting from the presentation of the feedback stimulus would allow fear to be reduced.

The present results also provide evidence against an avoidance conditioning theory proposed by Herrnstein (1969). He holds that avoidance responses are learned because they serve to reduce shock frequency and not because they serve to reduce fear. Herrnstein's theory seems unable to account for the inverse relationship between shock intensity and shuttlebox-avoidance performance. It would seem that reducing the frequency of strong shock should be more effective than reducing the frequency of weak shock, and hence, avoidance learning should be better with strong than with weak shock. Yet the opposite results were obtained. Further, the shock frequency reduction theory provides no basis for explaining the superiority of the large-reward as compared to the small-reward condition which was obtained in the present experiment with weak shock.

The use of discontinuous shock did not facilitate performance as was expected. Previous studies have found superior performance with discontinuous as compared to continuous shock in shuttleboxavoidance (Moyer \& Chapman, 1966) and discriminated barpress avoidance (e.g., D'Amato, Keller, \& Biederman, 1965) tasks when shock was on for $.2 \mathrm{sec}$ and off for $2.0 \mathrm{sec}$. Further, D'Amato et al. have shown that performance is degraded as shock-on time increases with a constant 2 -sec shockoff time. Therefore, the explanation for the lack of effect of the continuity-of-shock variable in the present experiment is probably attributable to the use of a nonoptimal shock-on duration $(.75 \mathrm{sec})$. This value was chosen, however, to avoid differential attrition in the groups, because in preliminary work it was found that with shorter shock-on times under the weak-shock condition many subjects did. not make escape responses.

\section{REFERENCES}

Anisman. H . d Waller. T. G. Facilitative and disruptive eftects of pror exposure to shock on subsequent avoidance pertormance. Joumal of Comparatuve and Phisiological Pyichology, 1972. 78. 113-122.

BAUER. R. H. The effects of CS and US intensity on shuttlebox avoidance. Psichonome Scance, 1972. 27, 266-268.

BINTZ. J. Between- and within-subject effect of shock intensity on avoidance in goldfish (Carassius auratus). Journal of Comparative and Physiological Psychology, 1971, 75, 92-97.

Boties. R C. Species-specitic detense reactions and avoidance learnng. Pswchologtcal Reve'w. 1970. 77, 32-48.

Bower. G . Starr. R. \& Lazarovitz. L. Amount of response. produced change in the CS and arodance learning. Joumal of Comparative and Phisulogical Psichology. 1965, 59. 13-17.
CAMPBEll. B. A The reinfurcement difference limen (RDL) function for shock reduction. Joumal of Expenmental Psichologi, 1956. 52. 258.262.

(amprell. B A.. \& Kraeling, D Response strength as a function of drive level and amount ot drive reduction. Journal of Expermental Psichologl: 1953. 45. 97.101.

(ICALA, G A., \& KREMER, E The eftects of shock intensits and d-amphetumine on arodance learning. Psychonomic Science. $1969,14,41-42$

DAmato, M. R. Expenmental psychology Methodology. psichophisess, and learning Neu York. McGrau-Hill. 1970.

D'amato. M. R.. Keller. D.. \& Biederman. G. Discriminated avoldance learning as a lunction of parameters of discontinuous shock. Journal of Experimental Psychology, 1965, 70, 543-548.

Dieter, S. E. Contiuity and intensity of shock in one-way avoidance learning. Animal Learning and Behavior, in press.

Franchita, J. J., Busii, M. E., Kash, J. S., Troen, D. M., \& Young, R. L. Similarity between shock and safe areas during acquisition. transter. and extinction of escape behavior in rats Journul of Compuratue and Physiological Psychology. 147,3,84, 216-224.

Freedman. P. E.. Hennessy. J. W.. \& Groner, D. Effects of varying active, passive shock levels in shuttle box avoidance in rats. Journal of Comparatwe and Phystological Psychology. 1974, 86, 79-84.

HeRrNStein, R. J Method and theory in the study of avoidance. Psichological Revewi, 1969, 76, 49-69.

KLRTZ. P. S.. \& Shafer. J. N. The interaction of UCS intensity and intertid interval in avoldance learning. Psichonomic Sce'nce. 190 - 8. 465-46h

LEVINF. S. UCS intensitr and arodance learning. Joumal of Expermmenal Psichology. 1966. 71, 163-164.

MCAli ister. W R..\& MCAllister, D. E. Role of the CS and of apparatus cues in the measurement of acquired fear. Psichological Reports. 1962. 11. 749-756.

Mc Alister. W. R.. McAllister. D. E.. \& Douglass. W. K. The merse relattonship between shock intensity and shutte-bos aroidance learning in rats. A reintorcement explandion Journal of Comparanve and Physiological Psichology. 19-1, 74, 426-433.

Modaresi. H. A One-ual charactersustic performance of rats under two-way signaled avoidance conditions. Learning and Motivation, 1975, 6, 484-497.

Mowrer, O. $H$. On the dual nature of learning-A re-interpretation of "conditioning" and "problem-solving." The Harvard Educattonal Revtew. 1947. 17, 102-148.

Moyfr. K. E.. a Chapman, J. A. Effect of continuous is drecontmuous shock on shuttle box avordance in the rat. Prychonomic Sirence. 1966, 4. 197-198

MOYER, K. E.. \& KORN, J. H. Effect of UCS intensity on the acquisition and extinction of an avoidance response. Joumal of Expermental Psichology', 1964. 67. 352-359.

Morer. K. E A Korn. J. H. Etfect of LCS intensity on the dequisturn and exunction of a one-1 as avordance response. Paychomome Scrence. 1960. 4. 121-122.

Iheios. J.. Lrnch. A D.. d Lowe, W. F., JR. Ditterential etfects of shock mtensit? on one-ray and shuttle avoldance cunditoung. Jourial of Experimental Psychology. 1966. 72. 244.294

(Recened for publecation Juls 30. 1975; rensun acepted Nowember 1.3.1975) 